\title{
Outdoor School Activities Strategy for Enhancing Student's Academic Achievement and Retention in Science in Delta South Senatorial District
}

\section{Edarho Oghenevwede Oyovwi (PhD)}

\author{
Department of Science Education, Faculty of Education, \\ Delta State University, P.M.B. 1, Abraka, Delta State, Nigeria
}

Doi: 10.36941/jesr-2020-0oo9

\section{Abstract}

The study examined the effects of outdoor science activities on student's academic achievement and retention in science in Delta South Senatorial District. The quasi-experimental design was used specifically, the non-equivalent pre-test, post-test control group design. Four research questions and hypotheses were raised and formulated to guide the study. The population consists of all senior secondary school two (SSII) science students in all the Government-owned public schools in the Senatorial District with an estimation of fifteen thousand, two hundred and seventy-five students $(15,275)$. A sample of two hundred and fifty $(250)$ SSII science student's randomly selected from four (4) public mixed secondary schools in the Senatorial District was used for the study. The instrument used for data collection was the Science Achievement Test (SAT) which was validated by experts in the field of Science, Measurement and Evaluation. The reliability of the instrument was established using Kuder-Richardson formula 21 which yielded coefficient of internal consistency of o.82. Data were collected by administering the Science Achievement Test (SAT) as a pre-test. Post-test and post-post-test (follow up test). The data obtained were analysed using mean, standard deviation, Analysis of Variance (ANOVA) and Analysis of Covariance (ANCOVA). The results showed that there was a significant difference in the mean achievement and retention scores between students taught using outdoor science activities and those taught without outdoor science activities. There was no significant difference in the mean achievement scores between male and female students taught science with outdoor science activities and there was a significant difference in the mean retention scores between male and female students taught science with outdoor science activities in favour of male students. Based on the findings, it was concluded that outdoor science activities may be an option in promoting students' academic achievement and retention in science students. Based on this, it was recommended that science teachers should adopt outdoor science activities in teaching science at the secondary school levels and that Government should provide an essential outdoor learning environment in schools to facilitate outdoor science activities.

Keywords: Outdoor Science Activities; Strategy; Achievement; Retention; Students

\section{Introduction}

Science as a field of study contributes to the development of society through the cultivation of scientific culture hence its role in any society cannot be overemphasized. Science also educates future generation in the acquisition of necessary knowledge, skills and attitude for coping with the everdemanding world of science and technology. In fact, the level of scientific attainment of a nation has always been a very important index for measuring its level of development. Nations are identified as developed or underdeveloped based on their scientific and technological attainment levels (Lawal, 
2009) which in turn determines the country's level of socio-economic as well as industrial development. Due to the slow rate in science and technological development in Africa and Nigeria in particular, they are seen and regarded as underdeveloped and developing when compared to countries like Japan, America and Britain that are today leading industrial nations as a result of their scientific knowledge and skill acquisition. The slow rate of development in Africa has been attributed to the slow rate of its scientific and technological development.

Science is an ordered arrangement of ascertained knowledge including the method by which such knowledge is extended and the criteria by which its truth is tested (Chamber Dictionary of Science and Technology). Abdulahi (1982) defined science as the activities of culminating falsifiable and verifiable body of knowledge about diving and non-diving components of the environment obtained by careful observation and testing of facts.

Considering the role of science in national development, the National Policy on Education emphasized the teaching and learning of science process and principles which will lead to fundamental and applied research in the sciences at all levels of education (Federal Republic of Nigeria, FRN, 2004). This will thus have aimed at producing large, qualitative manpower that has a good base in science and technology and generally a scientific literate society that can solve its own problems. The goals of science education were thus stipulated as follows:

- Cultivate inquiring, knowing and rational mind for the control of a good life and democracy

- Produce scientists for national development

- Service studies in technology and the cause of technological development and

- Provide knowledge and understanding of the complexity of the physical world, the form and the conduct of life.

Akpan (as cited in David \& Hudu, 2005) opined that the goals of science education could be subsumed under the following four categories:

- Personal needs which have to do with the preparation of an individual to use scientific knowledge in improving their lives and for coping with an increasingly developing technological world.

- Societal needs which play a crucial role in the development of an individual for life and hence students need to be prepared to be able to deal more responsibly with science-related societal issues.

- Academic preparation need which entails acquainting of the students who are likely to pursue science academically as well as professionally with the appropriate and adequate knowledge for such endeavour.

- Career awareness needs which are to sensitize as well as prepare students to make objective decisions about jobs related to science and technology.

Science education has always articulated a need to have students develop their thinking and reasoning skills towards achieving vocational competence by using adequate materials and tools. This paradoxical knowledge is based upon the proposition that through overt activity, the student will learn the concept of our individual world, which deal with the ways human beings think about and apply scientific theories and principles to change the physical environment to meet their aesthetic and utilitarian needs. It provides opportunities for developing the concept through concrete experience which include manipulation of materials, tools and process and other method of discovering leading to mastering leaning.

The use of outdoor science activities becomes necessary in the sense that outdoor science activities reduce abstraction, enhances lesson clarity, captivate students' attention and interest, encourage students' active participation and improve students' ability to remember learnt concept by providing the student with real-life experiences. Conway (2010) defined outdoor education as a method of teaching and learning process in the "outdoor" for exploration and discovery about the environment using the first-hand experience involving all sources of study. it is the kind of education in which the learner is naturally and actively engaged in having the first-hand experience in 
constructing his/her knowledge from resources or materials outside the normal school classroom and laboratory, mostly under instructional guide by a teacher or educator. Erickson-Dobrovich (2008) defined outdoor education as a method of learning with the use of all senses that takes place out-ofclassroom doors in a natural environment.

It is a complement to the classroom and to the traditional teaching method. It could be an extension of the traditional classroom lesson that is based on the role of nature and the environment as a teaching method or strategy. According to Dietz (2002), where teachers and educator teach science concepts indoors that are best taught outdoors, the concept is isolated from its natural context thereby limiting the full use and potential of a child's brain and this may lead to decontextualisation of the concepts if students are learning about concepts that naturally occur outside, they need to learn these concepts through active exploration using as many senses as possible. They are more likely to amass the total picture into a complete and accurate idea of the concept.

Carlson (2009) noted that outdoor activities are experiential by nature and the experience of being outside the classroom walls may stimulate students to learn in new ways. Hence, it is defined as those instructions either formal or informal that take place outside the school classroom and laboratory with natural or built material or place to attain the objectives of teaching and learning through direct experiences. Bartosh (2003) found out that learning based on the environment and the outdoor has been shown to improve student's academic achievement and standardized test scores. Ernst and Monroe (2004) discovered that such learning improve critical thinking skills.

In line with the above, outdoor science activities has been shown in a number of studies to positively improve student's achievement in various ways (Achor \& Amadu, 2015; Ahmed, 2014; Ajaja, 2010; Ogbeba \& Ajayi, 2016). This is because it gives students an explicit plan for improving their achievement in science through active engagement in having the first-hand experience in constructing knowledge from resources outside their normal school classroom. It also brings about effective teaching of environmental education and consequently the acquisition of problem-solving skills. Outdoor science education activities expose students to practical experience which not only reduces abstraction in the concept of learning but also stimulate student's interest in learning thereby enhancing student's subject matter conceptualization.

The evidence from the literature revealed that not much study has been explored on outdoor science activities in science in Delta Central Senatorial District to the best of the researcher's knowledge. This is the gap the study filled, to provide more empirical evidence on the effects of outdoor science activities on student's achievement and retention in sciences.

The purpose of this study is on outdoor science activities on students' academic achievement and retention in science. Specifically, the study:

i. compared the mean achievement scores of students taught science using outdoor science activities and those taught without science activities.

ii. compared the mean achievement scores of male and female students taught science using outdoor science activities.

iii. compared the mean retention scores of students taught science using outdoor science activities and those taught without outdoor science activities.

iv. compared the mean retention scores of male and female students taught science using outdoor activities.

The following research question guided the study:

1. Is there any difference between the mean achievement scores of students taught science using outdoor science activities and those taught without science activities?

2. Is there any difference between the mean achievement scores of male and female science students taught using outdoor science activities and those taught without outdoor science activities?

3. Is there any difference in the mean retention score of students taught science using outdoor science activities and those taught without outdoor science activities? 
4. Is there any difference in the mean retention score of male and female students taught science using outdoor science education activities and those taught without science education activities?

The following hypotheses were formulated and tested at 0.05 level of significance:

1. There is no significant difference between the mean achievement scores of students taught science using outdoor science activities and those taught without outdoor science activities.

2. There is no significant difference between the mean achievement scores of male and female science students taught science using outdoor science activities and those taught without outdoor science activities.

3. There is no significant difference between the mean retention of students taught science using outdoor science activities and those taught without outdoor science activities.

4. There is no significant difference between the mean retention of male and female students taught science using outdoor science activities and those taught without outdoor science activities.

\section{Method}

\subsection{Sample and Participant Selection}

The population of the study comprised of all senior secondary school II science students in government own public school with an estimation of 15,275 science student. A sample of 250 senior secondary school II (SSII) students from four (4) secondary schools in four Local Government Areas in Delta South Senatorial District was used for the study. The Simple Random Sampling Technique was used to draw the sample through balloting (replacement/ withdrawal).

\subsection{Assessment and Measures}

The instrument used for data collection was the Science Achievement Test (SAT), which was validated by a group of experts from Measurement and Evaluation science teachers in the Senatorial District. The reliability of the instrument (SAT) was established using the Kuder-Richardson Formula $\left(\mathrm{KR}_{20}\right)$. A reliability coefficient of internal consistency of 0.82 was obtained. Students were assigned to outdoor science activities groups (experimental group) and those without outdoor science activities (control group).

\subsection{Research Design}

The study examined outdoor science activities on student's academic achievement and retention in science in Delta South Senatorial District. The study adopted the pre-test, post-test non-equivalent control group quasi-experimental design.

\subsection{Experimental Intervention}

Four (4) intact classes were used randomly assigned to an experimental and control group respectively. The experimental group was exposed to outdoor science activities while the control groups were not exposed to science activities. The four teachers in the four selected schools were used as research assistants and were trained on the skills of using outdoor science activities. The treatment lasted for a period of five weeks. Before the commencement of treatment, both the experimental and control groups were pre-test with the item Science Achievement Test (SAT). This was done to determine the equivalent of the groups and be sure that any noticed change later was due to the treatment. Two days to the end of the treatment, the instrument (SAT) was administered to both the experimental and control groups as post-test. After two weeks, the SAT was administered 
again as follow-up-test (retention).

\subsection{Ethical Consideration}

Prior to the experiment, the researcher sought and obtained permission from the management of the various schools used for the study. Informed consent was thereafter obtained from the students, after being briefed on the nature and purpose of the study. The researcher explained to the students that the process was voluntary and that they were free to withdraw at any time they feel uncomfortable with the procedure. The students were assured of full confidentiality of their data. In order to protect them further, the researcher and research assistants ensured that no personal details that could be traced to any of the students were provided in the answer sheets.

\subsection{Statistical Analysis}

The pre-test, post-test and follow-up-test scores for each group were collated and analysed using mean, standard deviation, t-test, Analysis of Variance (ANOVA) and Analysis of Covariance (ANCOVA) tested at 0.05 level of significance.

\section{Results}

The results of the data analysis are presented in accordance with the research questions and corresponding hypotheses raised to guide the study.

Table 1. Mean and standard deviation of pre-test and post-test achievement scores of students taught science with outdoor science activities and those taught without science activities.

\begin{tabular}{lcccccc}
\hline Group & N & Pre-Test & SD & Post-Test & SD & Mean \\
\hline Students exposed to outdoor activities & 127 & 29.47 & 6.43 & 59.67 & 12.62 & 30.21 \\
Students not exposed to outdoor activities & 123 & 29.79 & 7.75 & 48.92 & 10.89 & 19.14 \\
\hline
\end{tabular}

Table 1 shows a mean achievement pre-test score of 29.47 with a standard deviation of 6.43 for students exposed to outdoor activities and a mean achievement pre-test score of 29.79 with a standard deviation of 7.75 for students not exposed to outdoor activities. As for the post-test, the table also shows a post-test mean achievement score of 59.67 with a standard deviation of 12.62 for students exposed to outdoor activities and a mean achievement score of 48.92 with a standard deviation of 10.89 for students not exposed to outdoor activities. The students exposed to outdoor activities had a higher mean gain of 30.21 compared to their counterpart that was not exposed to outdoor activities which had a mean gain of 19.14 .

Table 2. ANOVA comparison of the post-test score of students exposed to outdoor activities and those not exposed.

\begin{tabular}{lcccccc}
\hline & Sum of Squares & df & Mean Square & F & d & Sig. \\
\hline Between Group & 6281.339 & 1 & 6281.339 & & & \\
Within Group & 34798.974 & 250 & 139.196 & \multirow{2}{*}{52.316} & 0.15 & .0oo \\
Total & 42080.29 & 251 & & & \\
\hline
\end{tabular}

Table 2 shows that there is a significant difference between the mean achievement post-test scores of students exposed to outdoor activities and those not exposed to outdoor activities. 
Table 3. The mean and standard deviation of pre-test and post-test achievement scores of male and female students exposed to outdoor activities

\begin{tabular}{llccccc}
\hline Sex & N & Pre-test & SD & Post-Test & SD & Mean \\
\hline Male & 67 & 28.31 & 6.93 & 59.76 & 12.76 & 31.40 \\
Female & 60 & 30.76 & 5.60 & 59.60 & 12.61 & 28.80 \\
\hline
\end{tabular}

Table 3 shows a mean achievement pre-test score of 28.31 with a standard deviation of 6.93 for male students exposed to outdoor activities and a mean achievement pre-test score of 30.76 with a standard deviation of 5.60 for female students not exposed to outdoor activities. While the post-test shows a mean achievement score of 59.76 with a standard deviation of 12.76 for male students exposed to outdoor activities and a mean achievement score of 59.60 with a standard deviation of 12.61 for female students not exposed to outdoor activities. The male had a mean of 31.40 compared to their female counterpart which had a mean gain of 28.50 .

Table 4. ANCOVA comparison of post achievement scores of male and female students exposed to outdoor activities

\begin{tabular}{lccccc}
\hline Source & Type III Sum of Square & df & Mean Square & F & Sig. \\
\hline Corrected Model & 68.130 & 2 & 34.065 & .211 & .810 \\
Intercept & 22137.971 & 1 & 27137.971 & 136.834 & .000 \\
& 67.266 & 1 & 67.266 & .416 & .520 \\
Sex & .417 & 1 & .417 & .003 & .960 \\
Error & 20223.369 & 125 & 161.787 & & \\
Total & 476304.000 & 125 & & \\
Corrected Total & 20291.500 & 129 & & \\
\hline
\end{tabular}

A non-significant difference was found between the mean achievement post-test scores of male and female students exposed to outdoor activities.

Table 5. Mean and standard deviation of retention score of students exposed to outdoor activities as those not exposed.

\begin{tabular}{lccc}
\hline Group & N & Mean & SD \\
\hline Students exposed to outdoor activities & 127 & 57.42 & 7.22 \\
Students not exposed to outdoor activities & 123 & 50.56 & 8.74 \\
\hline
\end{tabular}

Table 5 shows a mean retention score of 57.42 with a standard deviation of 7.22 for students exposed to outdoor activities and a mean retention score of 50.56 with a standard deviation of 8.74 for students not exposed to outdoor activities in favour of students exposed to outdoor activities.

Table 6. The mean and standard deviation of retention score of male and female students exposed to outdoor activities

\begin{tabular}{lccc}
\hline Sex & N & Mean & SD \\
\hline Male & 67 & 56.42 & 11.31 \\
Female & 60 & 50.24 & 10.43 \\
\hline
\end{tabular}

Table 6 shows a mean retention score of 56.42 with a standard deviation of 11.31 for male students exposed to outdoor activities and a mean retention score of 50.29 with a standard deviation of 10.43 for female students. The result is in favour of male students. 


\section{Discussion}

From the result analysis and findings, there was a clear indication that students exposed to outdoor science activities performed better in their mean achievement scores than those not exposed to outdoor activities. This was as a result of the significant difference as recorded in Table 2, predicated on the fact that outdoor activities expose students to practical experiences which not only reduces abstraction in concept learnt but also stimulates students interest in learning thereby enhancing students subject matter conceptualization. This finding is in agreement with Oloyele and Asaaju (2016); Ogbeba and Ajayi (2016) who observed that outdoor activities significantly improve students' achievement and environmental problem-solving skills.

There was also a non-significant difference in the mean achievement scores between male and female students taught science with outdoor science activities. The implication of this finding is that outdoor science activities is not gender bias, which corroborates with the views of Anchor and Amadu (2015) and Saidu and Suleiman (2014). The study also revealed that there is no significant difference in the mean retention scores between students taught science with outdoor science education activities and those taught without outdoor science education activities in favour of students exposed to outdoor activities. This finding agrees with that of Anchor, Ogbebe and Amadu (2014). Finally, the study also revealed that male students exposed to outdoor activities were able to retain more of the content learnt than their female counterpart.

\section{Conclusion}

Based on the findings, it can be concluded that outdoor science activities significantly improve students' academic achievement and retention in science, enhance the academic achievement of male and female students and also improve the retention of male students more than their female counterparts.

\section{Recommendations}

The following are recommended based on the findings of the study:

1. Science teachers should attend a seminar, conference and workshops to get more knowledge on the skills of outdoor science activities.

2. Science teachers should endeavour to inculcate adequate hands-on activities into science lesson to provide science students with the needed practical experience

3. The government should provide enriched outdoor learning environment in schools to facilitate outdoor science activities

4. Science teachers should adopt the use of outdoor science activities in teaching science at the secondary school level since it enhances students' academic achievement.

\section{References}

Abdulahi, A. (1982). Science teaching in Nigeria. Ilorin: Atoto Press Ltd.

Ahmed, Y. (2014). Effects of field trip on retention and academic achievement in ecology among secondary school student in Zaria, Nigeria. Unpublished M.Sc. Dissertation, Ahmadu Bello University, Zaria.

Ajaja, O. P. (2010). Effects of field trips on learning outcome in biology. Journal of Human Ecology, 31(3), 171-177.

Anchor, E. E., \& Amadu, O. S. (2015). An examination of the extent to which school outdoor activities could enhance senior secondary two students' achievement in ecology. Journal of Education and E-Learning Research, 2(3), 35-41.

Anchor, E. E., Ogbeba, J., \& Amadu, O. S. (2014). Effects of school outdoor activities on senior secondary two (SSII) students' retention in ecology in Jalingo Metropolitan, Taraba, Nigeria. Nigeria Educational Forum, 22(2), 83-95. 
Bartosh $\mathrm{O}$ 2003. Environmental education: Improving student achievement. Unpublished M.Ed Dissertation, The Evergreen State College. Retrieved $13^{\text {th }}$ February 2019 from Available at http://www.seer.org/pages/research/Bartosh2003.pdf.

Carlson, J. (2009). Never finished, just begin a narrative history of L.R. shape and outdoor education. Edina, MN: Beaver's Pond Press

Conway, C. (2010). Outdoor and indoor education. Retrieved $13^{\text {th }}$ January 2019 from http://www.ericdigest.org/pre923/outdoor.htm.

David, L., \& Hudu, S. M. (2005). 'Science education: a vehicle for natural development, unity and democracy.' In L., Adeniji (Ed.), Unity, democracy and development in Nigeria in the $21^{\text {st }}$ century: Issues, challenges and way forward. Jilal Publishing Company.

Dietz, K. A. (2002). Influence of teaching in an outdoor classroom on kindergarten children. Comprehension and recall of a science lesson. Unpublished M.Ed. Dissertation, Louisiana State University.

Erickson-Dobrovich, L. (2005). Definition of outdoor education: Learning in motion project. Sweden: Uppsala.

Ernst, J., \& Monroe, M. (2004). The effects of environmental-based education on students thinking skills and disposition towards critical thinking. Environment Education Research, 10(4), 507-522.

Federal Republic of Nigeria (2004). National policy on education. Yaba: NERDC Press.

Lawal, F. K. (2009). Acquisition of entrepreneurial skills through biology education and the role of the biology teacher. $5 \mathrm{o}^{\text {th }}$ Annual Conference Proceeding of STAN, pp134-137.

Mohammed, K. O., \& Bello, S. (2010). The effects of science on the Nation. Nigeria Journal of Professional Teacher, $1(6), 29-41$.

Ogbeba, J., \& Ajayi, O. V. (2016). Effects of hands-on-activities on achievement and retention of senior secondary chemistry students in stoichiometry. ICSHER Journal, 2(2), 54-59.

Saidu, A. S., \& Suleiman, N. L. (2014). Effect of outdoor laboratory teaching strategy on academic performance among college of education students of different ability level in North-West Zone, Nigeria. The 2014 WEI International Academic Conference Proceeding, Bali, Indonesia. 